\title{
The genotype of the transporter associated with antigen processing gene affects susceptibility to colorectal cancer in Japanese
}

\author{
Takenori Yamauchi · Shouhei Takeuchi • \\ Naoki Maehara $\cdot$ Yoshiki Kuroda
}

Received: 30 January 2014/ Accepted: 4 March 2014/Published online: 7 May 2014

(c) The Japanese Society for Hygiene 2014

\begin{abstract}
Objective Although colorectal cancer (CRC) is one of the most frequent malignancies in Japan, the associated genetic factors remain to be elucidated. Functional loss of the transporter associated with antigen processing (TAP) 1 gene induces carcinogenesis. We investigated whether single nucleotide polymorphisms (SNPs) in the TAPl gene (rs735883) are associated with susceptibility to CRC in a Japanese population.

Methods The study participants were 143 cases and 243 clinical controls. After extracting DNA from their peripheral blood cells, genotyping was conducted by the polymerase chain reaction-restriction fragment length polymorphism method.

Results Participants with a mutated allele had an increased risk for CRC. The adjusted odds ratios for the $\mathrm{C} / \mathrm{T}, \mathrm{T} / \mathrm{T}$, and the mutation type $(\mathrm{C} / \mathrm{T}+\mathrm{T} / \mathrm{T})$ compared to that of wild type (C/C) were 2.27 [95\% confidence interval (CI), 1.43-3.67], 1.95 (95\% CI, 0.88-4.30), and 2.22 (95\% CI, 1.42-3.55), respectively. Furthermore, a significant trend in the rate of cases was observed with an increasing number of mutated alleles ( $P$ for trend $=0.0068$ ).

Conclusions The genotype of the TAP1 gene is associated with susceptibility to CRC.
\end{abstract}

Keywords Immune escape - TAP1 - Genetic polymorphism $\cdot$ Colorectal cancer $\cdot$ Japanese

T. Yamauchi $\cdot$ S. Takeuchi $\cdot$ Y. Kuroda $(\bowtie)$

Department of Public Health, Faculty of Medicine, University of

Miyazaki, Miyazaki 889-1692, Japan

e-mail: ykuroda@med.miyazaki-u.ac.jp

N. Maehara

Department of Surgical Oncology and Regulation of Organ Function, Faculty of Medicine, University of Miyazaki,

Miyazaki 889-1692, Japan

\section{Introduction}

According to a report by the International Agency for Research on Cancer (IARC), colorectal cancer (CRC) is one of the most lethal malignant neoplasms worldwide despite the decreasing mortality and incidence of CRC in developed countries. The age-standardized incidence and mortality due to CRC per 100,000 are 17.2 and 8.2, respectively [1]. In Japan, the age-standardized incidence of CRC, which accounts for $16.5 \%$ of all malignant neoplasms, is the third highest among all kinds of cancer. The age-standardized mortality of CRC is 14.8 in men and 8.4 in women [2].

CRC carcinogenesis is a complex and multifactorial process. As is often true with malignancies, the development of CRC is the result of interactions between environmental and genetic factors. Many epidemiological studies have confirmed the effects of environmental factors. A diet containing red or processed meats can markedly increase the risk of CRC [3]. Heavy alcohol intake and smoking are also associated with CRC prognosis [4]. As a consequence, the IARC reported that diet, exercise, and obesity are associated with CRC carcinogenesis. In contrast, genetic factors are also associated with susceptibility to CRC. Gender differences have been reported in both age-standardized incidence and mortality of CRC [1]. A personal or familial history of specific diseases (e.g., a personal history of chronic inflammatory bowel disease and a familial or personal history of adenomatous polyps) has also been considered a risk factor for CRC [4-9]. Although the biological mechanisms underlying the carcinogenesis of CRC are not fully understood, one of the proposed mechanisms is immune escape, which allows tumor cells to escape from immune surveillance.

The transporter associated with antigen processing (TAP) protein, a heterodimer of TAP1 and TAP2 
belonging to the major histocompatibility complex (MHC) class $\mathrm{I}$, is responsible for immune escape $[10,11]$. TAP translocates antigen peptides from the cytosol to the endoplasmic reticulum (ER) lumen and helps MHC class I molecules bind to antigen peptides [12, 13]. Several TAP1 gene polymorphisms have been identified, and antigen processing ability has been evaluated in many studies. Some of the polymorphisms were found to decrease the efficacy of antigen processing [14]. Recent studies have suggested that TAPl gene polymorphisms may increase the risk for vitiligo [15], nasopharyngeal carcinoma [16], and CRC via downregulation of MHC class I molecules [17]. However, few epidemiological studies have focused on the TAPl gene polymorphisms (rs735883). In this case-control study, we investigated the association of the TAPl genotype with susceptibility to CRC in relation to gender and smoking status.

\section{Materials and methods}

Study participants

A total of 143 Japanese CRC cases and 243 Japanese noncancer clinical controls were recruited. The cases were consecutive patients treated at the University of Miyazaki (UOM) Hospital and the University of Occupational and Environmental Health (UOEH) Hospital in Japan from September 1992 to December 2006. The controls were recruited from patients suffering from non-cancerous diseases in the hospitals near UOEH Hospital between September 1996 and September 2001. All cases were histologically diagnosed with CRC including ascending, transverse, and descending colon cancer as well as rectal cancer. The subjects' history of illness, residence, occupation, and smoking status were examined by a self-questionnaire. No patients who had been exposed to carcinogens, heavy metals, or radiation in their occupational history were included. All subjects were classified into two groups according to smoking status: the "never" group, composed of non-smokers; and the "smoker" group, composed of both current smokers and ex-smokers. All cases and controls were given an explanation of the nature of the study, and written informed consent was obtained from all participants. The Ethical Committee of UOM approved this study procedure on December 7, 2005 (approval number: 239).

Polymerase chain reaction (PCR) amplification and genotyping

Genomic DNA was extracted from peripheral blood lymphocytes with a DNA Extractor WB Kit (Wako Pure Chemical Industries, Osaka, Japan) according to the manufacturer's protocol. The single nucleotide polymorphisms (SNPs) (rs735883) are located on the intron 7 region of the TAPl gene, and the analysis of this SNP was carried out using a PCR-restriction fragment length polymorphism (PCR-RFLP) assay, as described previously [15]. Briefly, samples were subjected to 35 cycles of $30 \mathrm{~s}$ denaturing at $95{ }^{\circ} \mathrm{C}, 30 \mathrm{~s}$ annealing at $55^{\circ} \mathrm{C}$, and $30 \mathrm{~s}$ extension at $72{ }^{\circ} \mathrm{C}$, followed by a 5 min final extension with PCR primers $5^{\prime}$-GTGCTCTCACGTTCCAAGGA-3' and $5^{\prime}$-AGGAGTAGAGATAGAAGAACC- $3^{\prime}$. Subsequently, a 183 bp PCR product was digested with the MspI restriction enzyme and the restriction fragments were separated by agarose gel electrophoresis in TAE buffer. The wild-type $\mathrm{C}$ allele was digested into fragments of 161 and $22 \mathrm{bp}$, and the mutated type $\mathrm{T}$ allele was not digested.

Statistical analysis

Results are presented as mean \pm standard deviation (SD) for continuous variables. Pearson's Chi square tests were used for a categorical comparison of the data and for evaluating the probability of Hardy-Weinberg equilibrium. The prevalence of each genotype was examined with the Cochran-Armitage trend test. Welch's two-sample $t$ tests were used for numerical comparisons. Multivariate analysis was conducted using a multiple logistic regression model after adjusting for age, gender, or smoking status. A $P$ value $<0.05$ (two-tailed) was considered significant. Smoking status is associated with increasing risk of CRC [18], and there are many more male smokers than female smokers among the Japanese population. As gender and smoking status could be confounding factors, stratified analyses by gender and smoking status were conducted to exclude the effect of each factor. Power analysis was performed to determine the statistical power of Chi square tests. All statistical analyses were performed using $\mathrm{R}$ ver. 2.15.1.

\section{Results}

The general characteristics of the cases and the controls are shown in Table 1 . The mean age $( \pm \mathrm{SD})$ was $65.8( \pm 16.6)$ years for the controls and $63.9( \pm 10.9)$ years for the cases $(P=0.18)$. The frequencies of gender and smoking status were not significantly different between the cases and the controls $(P=0.12,0.18$, respectively). No significant difference was observed between the cases and the controls in terms of age, gender, and smoking status. The frequencies of the TAPl genotypes are shown in Table 2. The allele frequencies in the cases were allele C: 0.58 and allele T: 0.42 , and allele C: 0.67 and allele T: 0.33 in the controls. The odds ratio (OR) for allele $\mathrm{T}$ compared to allele $\mathrm{C}$ was 
Table 1 General characteristics of the controls and the CRC patients

\begin{tabular}{lll}
\hline & Controls & Cases \\
\hline $\begin{array}{l}\text { Age (years) } \\
\text { Gender (\%) }\end{array}$ & $65.8 \pm 16.6$ & $63.9 \pm 10.9$ \\
Female & $110(45.3)$ & $53(37.1)$ \\
$\quad$ Male & $133(54.7)$ & $90(62.9)$ \\
Smoking Status (\%) & & $76(53.1)$ \\
Never & $112(46.1)$ & $67(46.9)$ \\
Smoker & $131(53.9)$ & 143 \\
\hline Total & 243 &
\end{tabular}

Age is presented as mean \pm standard deviation. Gender and smoking status are presented as number of subjects. No significant difference was observed between cases and controls

Table 2 Associations between the TAPl genotype and CRC

\begin{tabular}{lllll}
\hline Genotype & Controls & Cases & $\begin{array}{l}\text { Crude OR } \\
(95 \% \mathrm{CI})\end{array}$ & $\begin{array}{l}\text { Adjusted OR } \\
(95 \% \mathrm{CI})\end{array}$ \\
\hline $\mathrm{C} / \mathrm{C}(\%)$ & $106(43.6)$ & $38(26.6)$ & - & - \\
$\mathrm{C} / \mathrm{T}(\%)$ & $115(47.3)$ & $91(63.6)$ & $\begin{array}{c}2.21 \\
(1.39-3.49) * *\end{array}$ & $\begin{array}{l}2.27 \\
(1.43-3.67)^{* *}\end{array}$ \\
& & & 1.78 & 1.95 \\
$\mathrm{~T} / \mathrm{T}(\%)$ & $22(9.05)$ & $14(9.79)$ & $\begin{array}{c}1.78-3.78) \\
(0.88-4.30)\end{array}$ \\
Total & 243 & 143 & & \\
$\mathrm{C} /$ & $137(56.4)$ & 105 & 2.14 & 2.22 \\
$\mathrm{~T}+\mathrm{T} /$ & & $(73.4)$ & $(1.37-3.34)^{* *}$ & $(1.42-3.55)^{* *}$ \\
$\mathrm{~T}(\%)$ & & & & \\
\hline
\end{tabular}

Crude OR and adjusted OR for age, gender and smoking status were estimated using Chi square statistic and multivariate logistic regression, respectively

$95 \%$ CI $95 \%$ confidence interval, $O R$ odds ratio

$* P<0.05$, ** $P<0.01$

$1.47[95 \%$ confidence interval (CI), 1.08-1.98, $P=0.013]$. The observed frequencies of the TAPl allele in the controls were consistent with the allele frequencies in Japanese. Hardy-Weinberg equilibrium was confirmed for the TAPl genotype in the controls $(P=0.31)$. The adjusted ORs for the $\mathrm{C} / \mathrm{T}$ and $\mathrm{T} / \mathrm{T}$ genotypes compared to the $\mathrm{C} / \mathrm{C}$ genotype were estimated to be 2.27 (95\% CI, 1.43-3.67) and 1.95 (95\% CI, 0.88-4.30), respectively. Furthermore, that for the mutation type $(\mathrm{C} / \mathrm{T}+\mathrm{T} / \mathrm{T})$ was 2.22 (95\% CI, 1.42-3.55). Although a significant difference was not observed in the T/T genotype, a significant trend on the rate of the cases was observed ( $P$ for trend $=0.0068$ ).

The results of the stratified analysis by smoking status are shown in Table 3. In the "never" group, the adjusted ORs were estimated to be 1.94 (95\% CI, 1.02-3.75) for the C/T genotype and 2.04 (95\% CI, 0.62-6.58) for the $\mathrm{T} / \mathrm{T}$ compared to the $\mathrm{C} / \mathrm{C}$ genotype. Those in the "smoker" group were calculated to be 2.84 (95\% CI, 1.43-5.92) for
$\mathrm{C} / \mathrm{T}$ and 1.98 (95 \% CI 0.64-5.83) for T/T. For the mutated type $(\mathrm{C} / \mathrm{T}+\mathrm{T} / \mathrm{T})$, the ORs were 1.95 (95\% CI 1.05-3.72) in the "never" group and 2.69 (95\% CI, 1.37-5.51) in the "smoker" group, respectively. The $P$ for the trend was 0.079 in the "never" group and 0.027 in the "smoker" group.

The results of the analysis stratified by gender are shown in Table 4. In the male group, the adjusted ORs were estimated to be 2.04 (95\% CI, 1.11-3.84) for the C/T genotype and 2.38 (95\% CI, 0.86-6.61) for the T/T genotype compared to the $\mathrm{C} / \mathrm{C}$ genotype. The ORs for the $\mathrm{C} / \mathrm{T}$ and $\mathrm{T} / \mathrm{T}$ were 2.91 (95\% CI, 1.40-6.32) and 1.45 (95\% CI, 0.36-5.10), respectively, in the female group. For the mutated type, the ORs were 2.09 (95\% CI, $1.15-3.87)$ in the male group and $2.63(95 \% \mathrm{CI}$, $1.29-5.62)$ in the female group. $P$ for the trend was 0.065 in the male group and 0.052 in the female group.

\section{Discussion}

A significant association was observed between the TAP1 genotype and $\mathrm{CRC}(\mathrm{C} / \mathrm{C}$ vs. $\mathrm{C} / \mathrm{T}+\mathrm{T} / \mathrm{T}$, adjusted $\mathrm{OR}, 2.22$, $P<0.01)$. Although the $\mathrm{C} / \mathrm{T}$ genotype was significantly associated with CRC (adjusted OR, 2.27, $P<0.01$ ), a significant association was not observed for the T/T genotype (adjusted OR, 1.95, $P=0.093$ ). Stratified analyses were conducted to exclude the effects of gender and smoking status, (Tables 3 and 4) and a significant association was observed between the TAPl genotype and CRC.

However, a significant association with CRC was observed only in the C/T genotype, not in the T/T genotype. It is likely that there were not enough participants to ensure the statistical power to detect an association between the T/T genotype and CRC. The statistical power of the Chi square test between the $\mathrm{C} / \mathrm{C}$ and $\mathrm{T} / \mathrm{T}$ genotypes was calculated to be 0.31 , although it was recommended to be larger than $0.8[19,20]$. In contrast, the statistical powers of the Chi square test among all genotypes $(\mathrm{C} / \mathrm{C}$, $\mathrm{C} / \mathrm{T}$, and $\mathrm{T} / \mathrm{T}$ ), and between the $\mathrm{C} / \mathrm{C}$ and $\mathrm{C} / \mathrm{T}$ genotypes, were estimated to be 0.92 and 0.92 , respectively. It is possible that the $\mathrm{T} / \mathrm{T}$ genotype shows a stronger immunity than the $\mathrm{C} / \mathrm{T}$ genotype and thus immune escape occurs less often in that genotype. Recent studies on TAP1-deficient mice indicate the existence of a compensatory mechanism. $\mathrm{CD} 8+\mathrm{T}$ cells have been reported to play an important role in tumor surveillance by the immune system [21, 22]. Although the population of $\mathrm{CD} 8+\mathrm{T}$ cells was diminished in the TAP1-deficient mice, compensatory increases in $\mathrm{CD} 3+$ and $\mathrm{CD} 4+\mathrm{T}$ cell populations were observed [23]. Furthermore, the TAPl-independent pathway compensates for antigen processing and CD8+ T cells functioned normally even in the TAP1-deficient mice in vivo [24]. It is 
Table 3 Associations between the TAP1 genotype and CRC when stratified by smoking status

Crude OR and adjusted OR for age and gender were estimated using Chi square statistic and multivariate logistic regression, respectively

$95 \%$ CI $95 \%$ confidence interval, $O R$ odds ratio

* $P<0.05$; ** $P<0.01$

Table 4 Associations between the TAP1 genotype and CRC when stratified by gender

Crude OR and adjusted OR for age and smoking status were estimated using Chi square statistic and multivariate logistic regression, respectively $95 \%$ CI $95 \%$ confidence interval, $O R$ odds ratio * $P<0.05$, ** $P<0.01$

\begin{tabular}{llllll}
\hline Smoking status & Genotype & Controls & Cases & Crude OR (95\% CI) & Adjusted OR (95 \% CI) \\
\hline Never & C/C (\%) & $51(45.5)$ & $24(31.6)$ & - & - \\
& $\mathrm{C} / \mathrm{T}(\%)$ & $53(47.3)$ & $45(59.2)$ & $1.80(0.97-3.36)$ & $1.94(1.02-3.75)^{*}$ \\
& $\mathrm{~T} / \mathrm{T}(\%)$ & $8(7.14)$ & $7(9.21)$ & $1.86(0.62-5.55)$ & $2.04(0.62-6.58)$ \\
& Total & 112 & 76 & & \\
Smoker & $\mathrm{C} / \mathrm{T}+\mathrm{T} / \mathrm{T}(\%)$ & $61(54.5)$ & $52(68.4)$ & $1.81(0.99-3.32)$ & $1.95(1.05-3.72)^{*}$ \\
& $\mathrm{C} / \mathrm{C}(\%)$ & $55(42.0)$ & $14(20.9)$ & - & - \\
& $\mathrm{C} / \mathrm{T}(\%)$ & $62(47.3)$ & $46(68.7)$ & $2.91(1.46-5.82)^{* *}$ & $2.84(1.43-5.92)^{* *}$ \\
& $\mathrm{~T} / \mathrm{T}(\%)$ & $14(10.7)$ & $7(10.4)$ & $1.96(0.68-5.64)$ & $1.98(0.64-5.83)$ \\
& $\mathrm{Total}$ & 131 & 67 & & \\
& $\mathrm{C} / \mathrm{T}+\mathrm{T} / \mathrm{T}(\%)$ & $76(58.0)$ & $53(79.1)$ & $2.74(1.39-5.38)^{* *}$ & $2.69(1.37-5.51)^{* *}$ \\
\hline
\end{tabular}

\begin{tabular}{llllll}
\hline Gender & Genotype & Controls & Cases & Crude OR (95 \% CI) & Adjusted OR (95 \% CI) \\
\hline Male & C/C (\%) & $55(41.4)$ & $25(27.8)$ & - & - \\
& C/T (\%) & $67(50.4)$ & $55(61.1)$ & $1.81(1.00-3.25)^{*}$ & $2.04(1.11-3.84)^{*}$ \\
& T/T (\%) & $11(8.27)$ & $10(11.1)$ & $2.00(0.77-5.22)$ & $2.38(0.86-6.61)$ \\
& Total & 133 & 90 & & \\
& $\mathrm{C} / \mathrm{T}+\mathrm{T} / \mathrm{T}(\%)$ & $78(58.6)$ & $65(72.2)$ & $1.83(1.03-3.25)^{*}$ & $2.09(1.15-3.87)^{*}$ \\
Female & $\mathrm{C} / \mathrm{C}(\%)$ & $51(46.4)$ & $13(24.5)$ & - & - \\
& $\mathrm{C} / \mathrm{T}(\%)$ & $48(43.6)$ & $36(67.9)$ & $2.94(1.41-6.15)^{* *}$ & $2.91(1.40-6.32)^{* *}$ \\
& $\mathrm{~T} / \mathrm{T}(\%)$ & $11(10.0)$ & $4(7.55)$ & $1.42(0.41-4.95)$ & $1.45(0.36-5.10)$ \\
& Total & 110 & 53 & & \\
& $\mathrm{C} / \mathrm{T}+\mathrm{T} / \mathrm{T}(\%)$ & $59(53.6)$ & $40(75.5)$ & $2.66(1.29-5.46)^{* *}$ & $2.63(1.29-5.62)^{* *}$ \\
\hline
\end{tabular}

likely that some compensatory function would work only in the case of the T/T genotype as the functional deficit of the $\mathrm{C} / \mathrm{T}$ genotype in the TAPl gene might not be enough to drive a compensating network. As a result, the immune escape of tumor cells could more likely be tolerated by the $\mathrm{C} / \mathrm{T}$ genotype.

The TAP protein plays an important role in antigen presentation mediated by MHC class I and this process is considered essential for immune surveillance against tumors and pathogens. The impairment of TAP function in tumor cells that induces loss of downregulation of class I molecules on the cell surface is considered one of the main mechanisms of immune escape in a variety of tumors [13, 25-31]. Furthermore, TAP1 gene polymorphisms lead to the loss of MHC class I antigen processing ability [32]. The TAP gene is also considered a member of the ATP-binding cassette superfamily, which is associated with membrane transportation of solutes such as ions. Molecules belonging to the ATP-binding cassette family have nucleotide-binding domains and interact with other molecules involved in genetic events, such as chromosome maintenance and DNA repair [33-35]. Our results indicate that the polymorphisms (rs735883) located on the intron 7 of the TAP1 gene were associated with CRC but the functional mechanism remains to be elucidated. One likely mechanism is exon skipping. According to a previous study, the SNP located on the intron could cause exon skipping and aberrant RNA splicing [36]. Furthermore, the E2F8 binding motif (TTTGCCGC) is located on intron 7 in the TAPl gene. E2F8 is a transcription factor that belongs to the E2F superfamily and regulates the expression of genes related to the cell cycle and apoptosis [37]. In the case of the T allele, the cytosine at the $3^{\prime}$ end is substituted to thymine and the aberrant binding site (TTTGCCGT) is generated. E2Fs generally bind to the binding site located on the promoter region or intron 1 [38] but it may be that the efficacy of splicing is affected by decreasing frequencies of E2F8 binding to the aberrant binding site. Further study is essential to clarify the functional mechanism that associates the polymorphisms (rs735883) with CRC.

The adjusted OR of the alcohol dehydrogenase enzyme (ADH2) gene was 1.92 (95 \% CI, 1.06-3.46) in a Japanese population [39]. Another study reported that the adjusted OR of the RAD18 gene, which is associated with DNA repair, was 2.10 (95\% CI, 1.00-4.40) [40]. An increased number of SNPs associated with CRC were identified recently in a genome-wide association study [41-43]. It is likely that a genetic difference may not be observed when exposure to a carcinogen is great $[44,45]$. In fact, the differences among genotypes are easily observed in non- 
smokers or light smokers compared to smokers [46, 47]. In the present study, a significant difference was observed in the $\mathrm{C} / \mathrm{T}$ genotype and the mutation type $(\mathrm{C} / \mathrm{T}+\mathrm{T} / \mathrm{T})$ despite stratification by smoking status. Thus, the TAPI genotype was strongly associated with susceptibility to CRC. As the adjusted ORs for the C/T genotype and the mutation type $(\mathrm{C} / \mathrm{T}+\mathrm{T} / \mathrm{T})$ were larger in the "smoker" group than in the "never" group, it is possible that the TAP1 gene polymorphism interacts with smoking status. The interaction between the TAPl genotype and smoking status was introduced into a logistic regression model. However, the interaction was not significant. Similarly, the adjusted ORs for the $\mathrm{C} / \mathrm{T}$ genotype and the mutation type $(\mathrm{C} / \mathrm{T}+\mathrm{T} / \mathrm{T})$ were larger in the female group than in the male group although the TAP1 gene is located not on the sex chromosomes but on chromosome 6. Although the interaction between the TAP1 genotype and gender was also introduced into a logistic regression model, it was not statistically significant either.

One of the limitations of our study was smoking status. The percentage of "smokers" $(46.9 \%)$ was less than that of controls $(53.9 \%)$ although it was not a significant difference. The rate of cigarette smoking decreases every year in Japan. The rate among males of age 60-69 years was $48.1 \%$ in 1992 and $34.8 \%$ in 2006. Higher rates may be found in certain regions. It is likely that there were fewer smokers in the present study because the recruitment period was longer for the cases than for the controls. It is also possible that the exact information about smoking status was not acquired for the cases. To adjust and exclude the effects of smoking, we conducted a logistic regression model analysis and a stratification analysis. The other limitation of our study was the diagnostic accuracy. The period for recruitment was 14 years, and the diagnostic accuracy is likely to have changed with marked improvements in medical examinations. Hence, the potential cases that were not diagnosed at that time might be included in the controls. However, CRC screening by the local authority began in 1992, at which point recruitment of cases also started. Furthermore, the controls were not healthy controls but clinical controls in our study. This limitation had less of an impact on the results of our study.

A significant association was found between the TAP1 gene polymorphisms (rs735883) and CRC. This suggests that those with the risk allele (T) have a higher susceptibility to CRC. In order to promote the high risk approach against the onset of CRC, additional studies of the association between rs735883 and other SNPs and between rs735883 and other carcinogens are required.

Acknowledgments This study was supported by a Grant from the University of Miyazaki. The funders had no role in study design, data collection and analysis, decision to publish, or preparation of the manuscript. This work was supported by the Faculty of Medicine of both the University of Miyazaki and the University of Occupational and Environmental Health. We give special thanks to Dr. Kazuo Chijiiwa, the staff and patients of the two facilities.

Conflict of interest We declare that none of the authors hold any financial or personal relationship with other people or organizations that could have inappropriately influenced this study.

\section{References}

1. Ferlay J, Shin H-R, Bray F, Forman D, Mathers C, Parkin DM. Estimates of worldwide burden of cancer in 2008: GLOBOCAN 2008. Int J Cancer. 2010;127:2893-917.

2. Matsuda A, Matsuda T, Shibata A, Katanoda K, Sobue T, Nishimoto $\mathrm{H}$. Cancer incidence and incidence rates in Japan in 2007: a study of 21 population-based cancer registries for the Monitoring of Cancer Incidence in Japan (MCIJ) project. Jpn J Clin Oncol. 2013;43:328-36.

3. Chao A, Thun MJ, Connell CJ, McCullough ML, Jacobs EJ, Flanders WD, et al. Meat consumption and risk of colorectal cancer. JAMA. 2005;293:172-82.

4. Phipps AI, Baron J, Newcomb PA. Prediagnostic smoking history, alcohol consumption, and colorectal cancer survival: the Seattle Colon Cancer Family Registry. Cancer. 2011;117:4948-57.

5. Duncan JL, Kyle J. Family incidence of carcinoma of the colon and rectum in north-east Scotland. Gut. 1982;23:169-71.

6. de Ponz Leon M, Sassatelli R, Sacchetti C, Zanghieri G, Scalmati A, Roncucci L. Familial aggregation of tumors in the three-year experience of a population-based colorectal cancer registry. Cancer Res. 1989;49:4344-8.

7. Gerdes H, Gillin JS, Zimbalist E, Urmacher C, Lipkin M, Winawer SJ. Expansion of the epithelial cell proliferative compartment and frequency of adenomatous polyps in the colon correlate with the strength of family history of colorectal cancer. Cancer Res. 1993;53:279-82.

8. Le Marchand L, Zhao LP, Quiaoit F, Wilkens LR, Kolonel LN. Family history and risk of colorectal cancer in the multiethnic population of Hawaii. Am J Epidemiol. 1996;144:1122-8.

9. Jass JR, Stewart SM. Evolution of hereditary non-polyposis colorectal cancer. Gut. 1992;33:783-6.

10. Ritz U, Seliger B. The transporter associated with antigen processing (TAP): structural integrity, expression, function, and its clinical relevance. Mol Med. 2001;7:149-58.

11. Cresswell P, Bangia N, Dick T, Diedrich G. The nature of the MHC class I peptide loading complex. Immunol Rev. 1999;172:21-8.

12. Antoniou AN, Powis SJ, Elliott T. Assembly and export of MHC class I peptide ligands. Curr Opin Immunol. 2003;15:75-81.

13. Seliger B, Maeurer MJ, Ferrone S. TAP off-tumors on. Immunol Today. 1997; 18:292-9.

14. McCluskey J, Rossjohn J, Purcell AW. TAP genes and immunity. Curr Opin Immunol. 2004;16:651-9.

15. Casp CB, She J-X, McCormack WT. Genes of the LMP/TAP cluster are associated with the human autoimmune disease vitiligo. Genes Immun. 2003;4:492-9.

16. Hassen E, Farhat K, Gabbouj S, Jalbout M, Bouaouina N, Chouchane L. TAP1 gene polymorphisms and nasopharyngeal carcinoma risk in a Tunisian population. Cancer Genet Cytogenet. 2007;175:41-6.

17. Yang T, Lapinski PE, Zhao H, Zhou Q, Zhang H, Raghavan M, et al. A rare transporter associated with antigen processing polymorphism overpresented in HLAlow colon cancer reveals the 
functional significance of the signature domain in antigen processing. Clin Cancer Res. 2005;11:3614-23.

18. Johnson CM, Wei C, Ensor JE, Smolenski DJ, Amos CI, Levin B, et al. Meta-analyses of colorectal cancer risk factors. Cancer Causes Control. 2013;24:1207-22.

19. J Cohen. Statistical power analysis. Curr Dir Psychol Sci. 1992;1:98-101.

20. Cohen J. A power primer. Psychol Bull. 1992;112:155-9.

21. Nagaraj S, Gupta K, Pisarev V, Kinarsky L, Sherman S, Kang L, et al. Altered recognition of antigen is a mechanism of CD8+ T cell tolerance in cancer. Nat Med. 2007;13:828-35.

22. Afshar-Sterle S, Zotos D, Bernard NJ, Scherger AK, Rödling L, Alsop AE, et al. Fas ligand-mediated immune surveillance by $\mathrm{T}$ cells is essential for the control of spontaneous B cell lymphomas. Nat Med. 2014;20(3):283-90.

23. Kolbus D, Ljungcrantz I, Söderberg I, Alm R, Björkbacka H, Nilsson J, et al. TAP1-deficiency does not alter atherosclerosis development in Apoe-/- mice. PLoS One. 2012;7:e33932.

24. Medina F, Ramos M, Iborra S, de León P, Rodríguez-Castro M, Del Val M. Furin-processed antigens targeted to the secretory route elicit functional TAP1-/-CD8+ T lymphocytes in vivo. J Immunol. 2009;183:4639-47.

25. Kasajima A, Sers C, Sasano H, Jöhrens K, Stenzinger A, Noske $\mathrm{A}$, et al. Down-regulation of the antigen processing machinery is linked to a loss of inflammatory response in colorectal cancer. Hum Pathol. 2010;41:1758-69.

26. Seliger B. Molecular mechanisms of MHC class I abnormalities and APM components in human tumors. Cancer Immunol Immunother. 2008;57:1719-26.

27. Lankat-Buttgereit B, Tampé R. The transporter associated with antigen processing: function and implications in human diseases. Physiol Rev. 2002;82:187-204.

28. Zheng P, Sarma S, Guo Y, Liu Y. Two mechanisms for tumor evasion of preexisting cytotoxic T-cell responses: lessons from recurrent tumors. Cancer Res. 1999;59:3461-7.

29. Zheng P, Guo Y, Niu Q, Levy DE, Dyck JA, Lu S, et al. Protooncogene PML controls genes devoted to MHC class I antigen presentation. Nature. 1998;396:373-6.

30. Seliger B, Ritz U, Abele R, Bock M, Tampé R, Sutter G, et al. Immune escape of melanoma: first evidence of structural alterations in two distinct components of the MHC class I antigen processing pathway. Cancer Res. 2001;61:8647-50.

31. Yang T, McNally BA, Ferrone S, Liu Y, Zheng P. A singlenucleotide deletion leads to rapid degradation of TAP-1 mRNA in a melanoma cell line. J Biol Chem. 2003;278:15291-6.

32. Chen HL, Gabrilovich D, Tampé R, Girgis KR, Nadaf S, Carbone DP. A functionally defective allele of TAP1 results in loss of MHC class I antigen presentation in a human lung cancer. Nat Genet. 1996;13:210-3.

33. Borst P, Elferink RO. Mammalian ABC transporters in health and disease. Annu Rev Biochem. 2002;71:537-92.

34. Holland IB, Blight MA. ABC-ATPases, adaptable energy generators fuelling transmembrane movement of a variety of molecules in organisms from bacteria to humans. J Mol Biol. 1999;293:381-99.

35. Hopfner KP, Karcher A, Shin DS, Craig L, Arthur LM, Carney JP, et al. Structural biology of Rad50 ATPase: ATP-driven conformational control in DNA double-strand break repair and the ABC-ATPase superfamily. Cell. 2000;101:789-800.

36. Khan SG, Muniz-Medina V, Shahlavi T, Baker CC, Inui H, Ueda $\mathrm{T}$, et al. The human XPC DNA repair gene: arrangement, splice site information content and influence of a single nucleotide polymorphism in a splice acceptor site on alternative splicing and function. Nucleic Acids Res. 2002;30:3624-31.

37. Xanthoulis A, Tiniakos DG. E2F transcription factors and digestive system malignancies: how much do we know? World J Gastroenterol. 2013;19:3189-98.

38. Wong JV, Dong P, Nevins JR, Mathey-Prevot B, You L. Network calisthenics: control of E2F dynamics in cell cycle entry. Cell Cycle. 2011;10:3086-94.

39. Matsuo K, Wakai K, Hirose K, Ito H, Saito T, Suzuki T, et al. A gene-gene interaction between ALDH2 Glu487Lys and ADH2 His47Arg polymorphisms regarding the risk of colorectal cancer in Japan. Carcinogenesis. 2006;27:1018-23.

40. Kanzaki H, Ouchida M, Hanafusa H, Sakai A, Yamamoto H, Suzuki H, et al. Single nucleotide polymorphism in the RAD18 gene and risk of colorectal cancer in the Japanese population. Oncol Rep. 2007;18:1171-5.

41. Jaeger E, Webb E, Howarth K, Carvajal-Carmona L, Rowan A, Broderick $\mathrm{P}$, et al. Common genetic variants at the CRAC1 (HMPS) locus on chromosome 15q13.3 influence colorectal cancer risk. Nat Genet. 2008;40:26-8.

42. Houlston RS, Webb E, Broderick P, Pittman AM, Di Bernardo $\mathrm{MC}$, Lubbe S, et al. Meta-analysis of genome-wide association data identifies four new susceptibility loci for colorectal cancer. Nat Genet. 2008;40:1426-35.

43. Peters U, Jiao S, Schumacher FR, Hutter CM, Aragaki AK, Baron $\mathrm{JA}$, et al. Identification of genetic susceptibility loci for colorectal tumors in a genome-wide meta-analysis. Gastroenterology. 2013;144:799-807.

44. Khoury MJ, Adams MJ, Flanders WD. An epidemiologic approach to ecogenetics. Am J Hum Genet. 1988;42:89-95.

45. Amos CI, Caporaso NE, Weston A. Host factors in lung cancer risk: a review of interdisciplinary studies. Cancer Epidemiol Biomarkers Prev. 1992;1:505-13.

46. Wang YC, Chen CY, Chen SK, Chang YY, Lin P. p53 codon 72 polymorphism in Taiwanese lung cancer patients: association with lung cancer susceptibility and prognosis. Clin Cancer Res. 1999;5:129-34.

47. Arizono K, Osada Y, Kuroda Y. DNA repair gene hOGG1 codon 326 and XRCC1 codon 399 polymorphisms and bladder cancer risk in a Japanese population. Jpn J Clin Oncol. 2008;38:186-91. 